\title{
An Exploratory Excursion To Test For Realignment Among Central Arkansans
}

\author{
Michael A. Niggel \\ Hendrix College
}

Abstract: An additive realignment model is designed and tested using the recently developed del statistics, partial correlations, and multivariate regression analysis. A path correlation model measures the effect of party identification, the voters'images of the parties, and several salient issues on central Arkansans' vote preferences for governor and president in 1980. A strong interrelationship between economic and international issues is identified, and the powerful association found between party identification, issues, and images of the parties suggests that the increase in Republican noting in 1980 may have been the result of a realignment of the Arkansas electorate.

Since the late 1950 's and early 1960 's, political scientists have scrutinized America's changing electorate, and a debate between two theoretical explanations of voting behavior, dealignment versus realignment, has developed within the discipline. Dealignment is a process in which traditional political party coalitions dissolve without new allegiances to parties or coalitions of social groups with parties being formed to take their places. ${ }^{1}$ Gerald Pomper, one of the leading proponents of dealignment, asserts that the American political parties are dying, and that the electorate chooses candidates mainly on the basis of issue positions. ${ }^{2}$ Paul Allen Beck also supports the dealignment theory; however, he believes that the postwar socialization process caused many young voters to avoid party affiliation, and instead select the nonpartisan status of Independent. ${ }^{3}$

Realignment, conversely, is a decrease in the proportion of 
the electorate affiliated with the majority party and an increase in the proportion of the electorate identified with the minority party. Walter Dean Burnham, one of the original supporters of realignment, identified three realignments that have occurred over the course of modern American political history. ${ }^{4}$ The most recent of these shifts in partisan allegiance was the emergence of the New Deal Democrats in 1932.

After the Democratic Party reversed its position on the race issue, Southern white conservatives became logical and ripe candidates for conversion to Republicanism. In Arkansas, the Republicans appeared to be gaining ground with Nixon's landslide victory in 1972, but by the middle 1970's Arkansas' electorate reverted to its traditional pattern of Democratic solidarity. In 1980, Republican victories in the presidential, congressional, and gubernatorial races renewed speculation of a realignment in Arkansas. ${ }^{5}$

The results of a survey in central Arkansas revealed strong evidence that economic and international issues were closely linked to party identification, partisan images, and candidate preferences. ${ }^{6}$ Moreover, these variables displayed a moderate amount of interaction and reinforcement. To test for the occurrence of a realignment among central Arkansans, this paper presents a model developed from a vote choice model designed by the Survey Research and Voting Behavior class at Hendrix College. ${ }^{7}$ (See Figure One.)

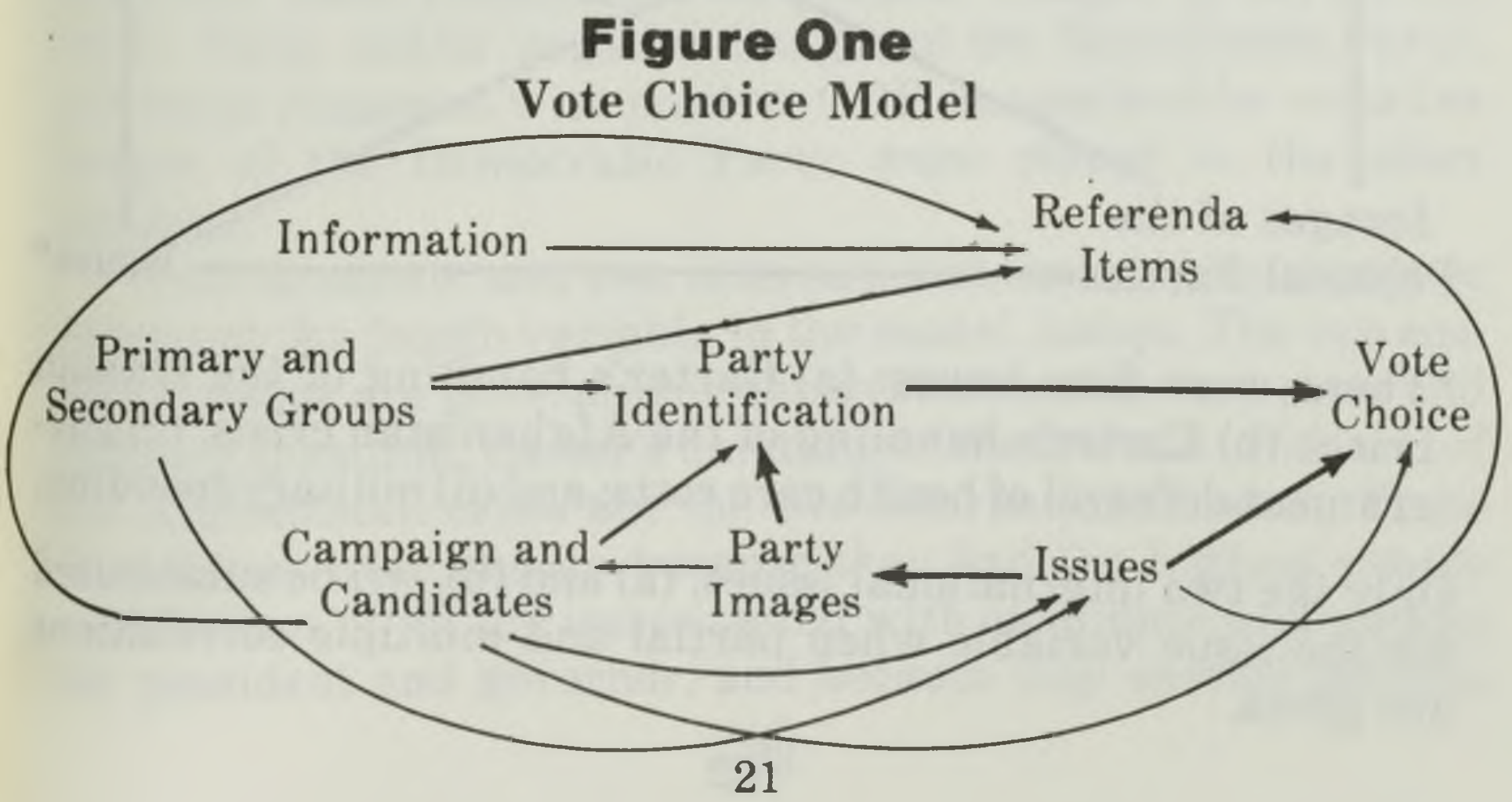


This complex vote choice model was developed to identify the magnitudes and directions of the major variables that may have exhibited significant influence during the 1980 election. If a realignment did transpire, it may be visible in the simple correlations between (and multiple correlations among) issues, party affiliation, images of the political parties and vote choice. The effect of these four variables, therefore, can be tested by a realignment model such as the one illustrated in Figure Two.

\section{Figure Two \\ Realignment Model}

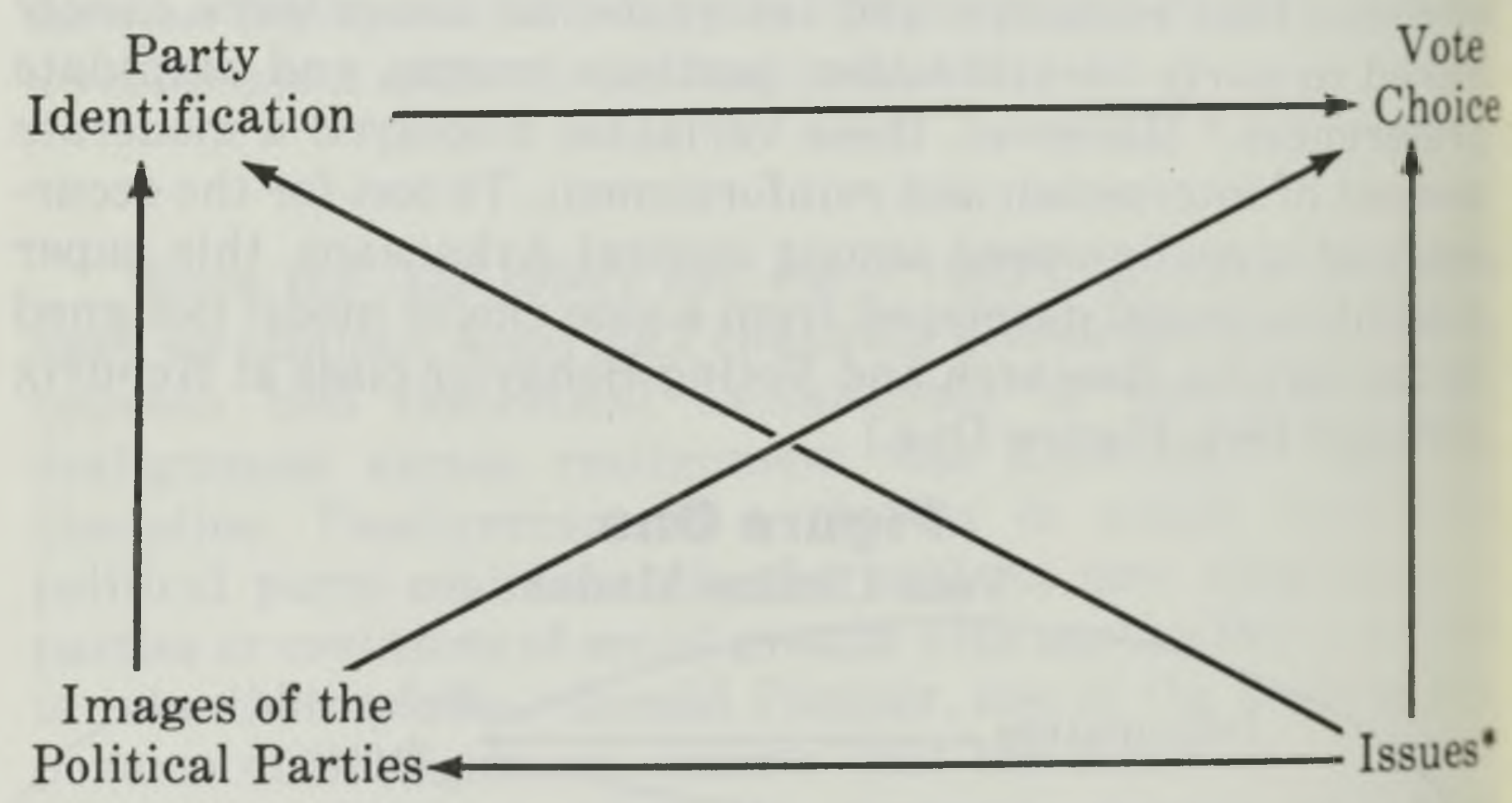

*There were four issues: (a) Carter's handling of the Iranian crisis; (b) Carter's handling of the Afghanistan crisis; (c) government defrayal of health care costs; and (d) military spending.

Only the two international issues, (a) and (b), wil be substituted for the issue variable when partial and multiple correlations are given. 


\section{The Variables}

The dependent variable in the realignment model is vote choice. Since vote choice can not be directly measured - the Australian ballot prevents that - an indirect measure is needed for vote choice. Pre-election candidate preferences as expressed in the 1980 Hendrix Central Arkansas Survey will be used to measure vote choice because they are the traditional surrogates, and their predictive utility in the Hendrix survey was exceptional. ${ }^{8}$ Candidate preferences for the office of president and governor represent the vote choice variable in this model because the number of undecideds on these two offices was small, and the Republican Party won surprising victories in both contests. ${ }^{9}$

Party identification is an independent variable in this realignment model, and it is measured by the traditional survey questions and the seven point ladder scale used by the Survey Research Center (now the Center for Political Studies). ${ }^{10}$ Historically, this variable has been the strongest predictor of vote choice. ${ }^{11}$

Party images is another independent variable, and the respondents' images of the parties were identified by asking these open-ended questions: "What do you like and/or dislike about the Democrats," and "What do you like and/or dislike about the Republicans?" After analyzing all of the responses, two dichotomous categories were constructed: one category contained those responses with positive images of the Democratic Party and/or negative images of the Republican Party, and those responses with positive GOP images and/or negative images of the Democratic Party were placed in the other category.

Two economic and two international issues were chosen to represent the fourth variable in the model, issues. The two economic issues are government defrayal of health care costs and military spending. Carter's handling of the Iranian crisis and of the Afghanistan crisis are the two international issues. These four issues were chosen because they had the highest simple correlations of all the issues tested with candidate preferences for president and governor, and because they showed definite 
potential for being interrelated with the other three variables used in this realignment model. ${ }^{12}$

\section{Interconnection Between Economic and International Issues}

Before attempting to demonstrate simultaneous connections among the four variables, the interrelationships between each of the variables, especially the economic and international issues, must be demonstrated. To find the degree of association between the economic and international issues, simple correla. tion statistics were computed. ${ }^{13}$ (See Table One.) The correlation between those respondents who supported government defrayal of health care costs and President Carter's handling of the Iranian crisis showed the highest degree of association $\nabla l=.27$, $p<.001$ ) among any of the pairs of economic and international issues tested, but all four of the relationships tested were statistically significant and moderately supportive of the hypothesized relationship between economic and international issues. A tentative conclusion, therefore, is that the economic and international issues tested are interconnected by an underlying ideological dimension, and that many other economic and international issues, such as priority of government functions (schools, housing, protection), U.S. acceptance of Cuban refugees, government guarantee of jobs and/or standard of living, and international trade protectionism are similarly interrelated, although probably not as strongly. ${ }^{14}$ 


\section{Table One \\ Correlations between Economic and International Issues}

\section{Economic}

Government defrayal of health vs. care costs

(all to none)

Government defrayal of health care costs (all to none)

Military spending (less or the same vs. more)

Military spending (less or the same vs. more)

\section{International}

Carter's handling of the

Iranian crisis

(good to poor)

vs. Carter's handling of the Afghanistan crisis (good or adequate vs. poor)

vs. Carter's handling of the Afghanistan crisis (good or adequate vs. poor)

vs. Carter's handling of the Iranian crisis (good job or some mistakes vs. many mistakes or poor job)
Statistic/Coefficient and Probability

$\nabla l=.27, \mathrm{p}<.001$

$\nabla l=.22, \mathrm{p}<.01$

$\nabla \mathrm{k}=.23, \mathrm{p}<.005$

(using chi-square)

$\nabla \mathrm{k}=.14, \mathrm{p}<.005$

(using chi-square) 


\section{Bond Between International Issues and Partisanship}

Naturally, both the economic and international issues should be examined within the framework of this realignment model, but extensive, time-consuming hand tabulations of the data prevented all four issue questions from being substituted into the issue variable of the model. Two issues were selected on the basis of their strength of association with candidate preferences for president and governor in 1980. These two issues, Carter's handling of the Iranian crisis and his handling of the Afghanistan crisis, exhibited correlations over twice the mag. nitude of the next highest issue. ${ }^{15}$

To test the bond between each of these two issues and partisanship, simple correlations between Carter's handling of each of these two international crises and the respondents' images of the parties were calculated. (See Tables Two and Three.) Both correlations, $\nabla_{\kappa}=.55$ and $\nabla_{\kappa}=.50$, indicate strong associations between international issues and images of the political parties,

\section{Table Two \\ Carter's Handling of the Afghanistan Crisis by Images of the Political Parties}
Respondents' images
Carter did a good of the political parties or adequate job
Carter did a poor job

\begin{tabular}{|c|c|c|}
\hline $\begin{array}{c}\text { Positive Democratic Party } \\
\text { and/or negative GOP }\end{array}$ & $\begin{array}{c}84.4 \% \\
(81)\end{array}$ & $\begin{array}{c}29.4 \% \\
(15)\end{array}$ \\
\hline $\begin{array}{c}\text { Positive Republican Party } \\
\text { and/or negative } \\
\text { Democratic Party }\end{array}$ & $\begin{array}{c}15.6 \% \\
(15)\end{array}$ & $\begin{array}{c}70.6 \% \\
(36)\end{array}$ \\
\hline $\begin{array}{c}\text { Total } \\
(\mathrm{N}=147)\end{array}$ & $(96)$ & \\
\hline
\end{tabular}

$\nabla \mathrm{k}=.55, \mathrm{p}<.001 \quad$ (using chi-square) 


\section{Table Three}

\section{Carter's Handling of the Iranian Crisis by Images of the Political Parties}
Respondents' images of the political parties

Carter did a good job or made some mistakes
Carter made many mistakes or did a poor job

\begin{tabular}{|c|c|c|}
\hline $\begin{array}{c}\text { Positive Democratic Party } \\
\text { and/or negative GOP }\end{array}$ & $\begin{array}{c}81.9 \% \\
(86)\end{array}$ & $\begin{array}{c}31.3 \% \\
(16)\end{array}$ \\
\hline $\begin{array}{c}\text { Positive Republican Party } \\
\text { and/or negative } \\
\text { Democratic Party }\end{array}$ & $\begin{array}{c}18.1 \% \\
(19)\end{array}$ & $\begin{array}{c}68.7 \% \\
(35)\end{array}$ \\
\hline Total & & \\
$(\mathrm{N}=156)$ & $(105)$ & \\
\hline
\end{tabular}

$\nabla \mathrm{k}=.50, \mathrm{p}<.001 \quad$ (using chi-square)

but further analysis is required to infer that strong connections between international issues and partisanship exist. Usually, party identification is a much better and more stable indicator of partisanship than are images of the parties. Hence, tests for associations between each issue and the respondents' party identification were performed. (See Tables Four and Five.) The reasonably strong associations found, $\nabla l=.41$ and $\nabla l=.25$, reinforce the hypothesis that the respondents' issue decisionmaking process included partisan dimensions. The relationship among international issues, party images and party identification is further buttressed by the association between party images and party identification, which is $\nabla_{\kappa}=.32, \mathrm{p}<.01$ (using chi-square). ${ }^{16}$

If a realignment did occur in central Arkansas, the ideological dimension that logically connects issues, party images, and party identification is most probably conservatism. Conservative Democrats and Independents may have shifted their party allegiance and vote choice, at least temporarily, to the 
GOP. The important question at this point is how much influence did the respondents' stand on international issues, their images of the parties, and their party affiliation have on their vote choice for both president and governor?

\section{Table Four \\ Carter's Handling of the Iranian Crisis by Party Identification}

\begin{tabular}{|c|c|c|}
\hline Respondent's & $\begin{array}{l}\text { Carter did a good } \\
\text { job or made }\end{array}$ & $\begin{array}{c}\text { Carter made many } \\
\text { mistakes or }\end{array}$ \\
\hline
\end{tabular}

\begin{tabular}{|c|c|c|}
\hline Democrat & $\begin{array}{c}72.4 \% \\
(131)\end{array}$ & $\begin{array}{c}28.7 \% \\
(37)\end{array}$ \\
\hline Independent* & $\begin{array}{c}13.2 \% \\
(24)\end{array}$ & $\begin{array}{c}20.9 \% \\
(27)\end{array}$ \\
\hline Republican & $14.4 \%$ & $\begin{array}{c}\text { (26) } \\
(65)\end{array}$ \\
\hline Total & $(181)$ & \\
\hline (N $=310)$ & & $(129)$ \\
\hline
\end{tabular}

$\nabla l=.41, \mathrm{p}<.001$

*Independent category includes Democratic leaners because both traditionally vote as "functional" Republicans. (See Wolfinger and Arseneau, 1978.) 


\section{Table Five}

Carter's Handling of the Afghanistan Crisis by Party Identification

\begin{tabular}{|c|c|c|c|}
$\begin{array}{c}\text { Respondents' } \\
\text { party identification }\end{array}$ & $\begin{array}{c}\text { Carter did } \\
\text { a good job }\end{array}$ & $\begin{array}{c}\text { Carter did an } \\
\text { adequate job }\end{array}$ & $\begin{array}{c}\text { Carter did } \\
\text { a poor job }\end{array}$ \\
\hline Democrat & $\begin{array}{c}82.4 \% \\
(47)\end{array}$ & $\begin{array}{c}61.5 \% \\
(72)\end{array}$ & $\begin{array}{c}36.3 \% \\
(45)\end{array}$ \\
\hline Independent* & $12.3 \%$ & $\begin{array}{c}18.8 \% \\
(22)\end{array}$ & $\begin{array}{c}17.7 \% \\
(22)\end{array}$ \\
\hline Republican & $(7)$ & $19.7 \%$ & $46.0 \%$ \\
& $5.3 \%$ & $(23)$ & $(57)$ \\
\hline Total & $(3)$ & & $(124)$ \\
\hline (N 298) & $(57)$ & $(11)$ & \\
\hline
\end{tabular}

$\nabla l=.25, \mathrm{p}<.01$

*Independent category includes Democratic leaners because both traditionally vote as "functional" Republicans. (See Wolfinger and Arseneau, 1978.)

\section{A Methodological Digression}

Partial and multiple correlations will be calculated to test the group effect of the three independent variables on vote choice. As the reader may have noticed, the correlation statistics used in this study are not the traditional proportional reductionof-error measurements, such as lambda, gamma, and Pearson's $\tau$. The del statistics $(\nabla \kappa, \nabla l, \nabla \mathrm{n})$ used in this study are deviation from perfect-association measures which are comparable to each other, although $\kappa, l$, and $n$ are for nominal, ordinal, and interval data, respectively. ${ }^{17}$ Two conditions are applicable when considering the del statistics; del $\mathrm{n}$ is comparable in magnitude to a Pearson's $\tau$ when the association between the 
variables is linear, and del $n$ magnitudes are comparable to del $\kappa$ and del $l$ magnitudes. Since product-moment correlations (i.e., Pearson's $\tau$ ) assume linearity, this study, therefore, assumes that all of the relationships here are linear, so that del $\kappa$ and del $l$ values may be substituted for $\tau$ values in order to compute multiple and partial correlations.

In addition, good causal models include these three elements: (1) "a finite set of explicitly defined variables, (2) certain assumptions about how these variables are interrelated causally, and (3) assumptions to the effect that outside variables, while operating, do not have confounding influences that disturb the causal patterning among the variables explicitly being considered."18 This experimental path correlation model assumes, only for the sake of this exploration, that there is no two-way causality between any of the variables. Furthermore, this study assumes that the four variables utilized in the realignment model operate within an isolated or "closed" system which does not take into consideration the effect of any outside variables-indeed quite dramatic and heroic assumptions. Yet, in fact, a newly designed and tested dynamic model depicts how the campaign and vote choice-internal, not external variables - can modify and reinforce (in a circular fashion) prior orientations, i.e., party identification and issue stands. ${ }^{19}$ Thus, the assumptions of this realignment model are relatively plausible, but they do not exploit the full complexity of the interrelationships.

\section{Path Correlation Analysis}

Path correlation analysis requires that partial correlation coefficients be calculated between all possible two-variable combinations in the model. In this model, there are seven different combinations of three variables (each of which requires three two-variable correlations) due to the substitution of the Iranian and Afghanistan questions for the issue variable. The directions and magnitudes of the partial correlations for each combination of variables are given in Figure Three. Both of the international issues and the images variable reflect a high 


\section{Figure Three}

Partial Correlations for Three-Variable Combinations*

A.

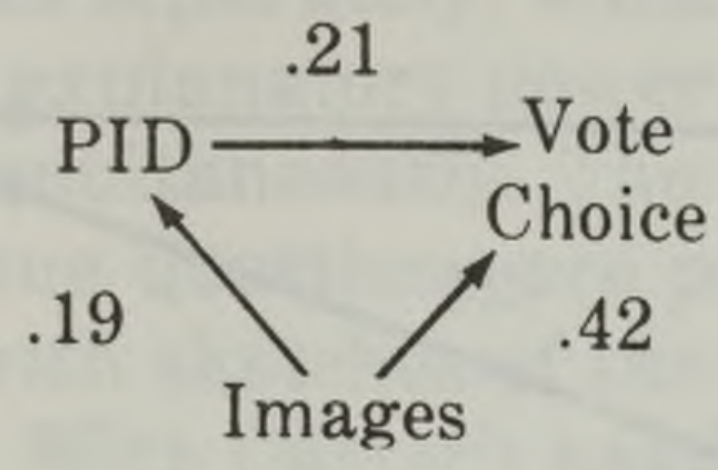

C.

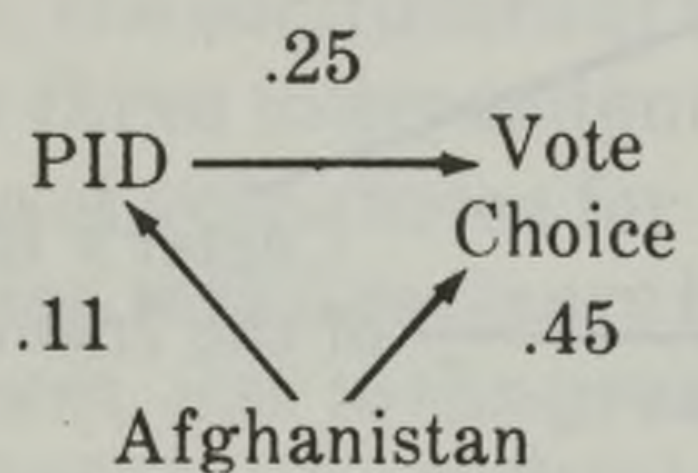

.30

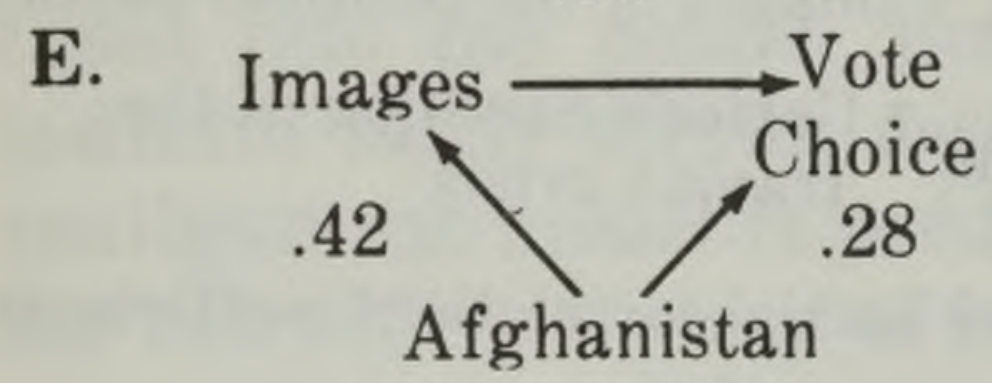

G.

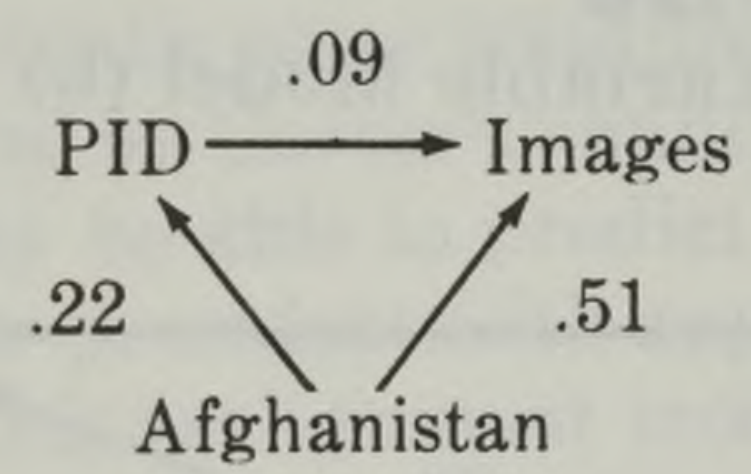

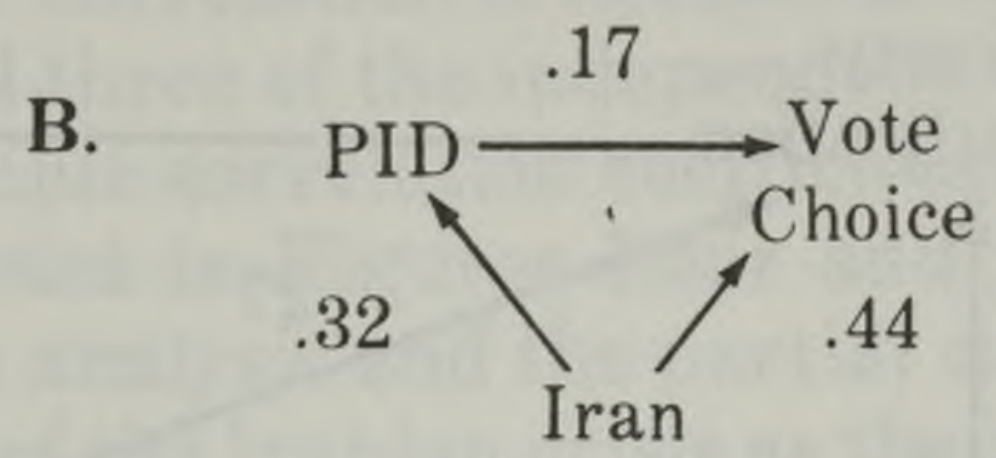

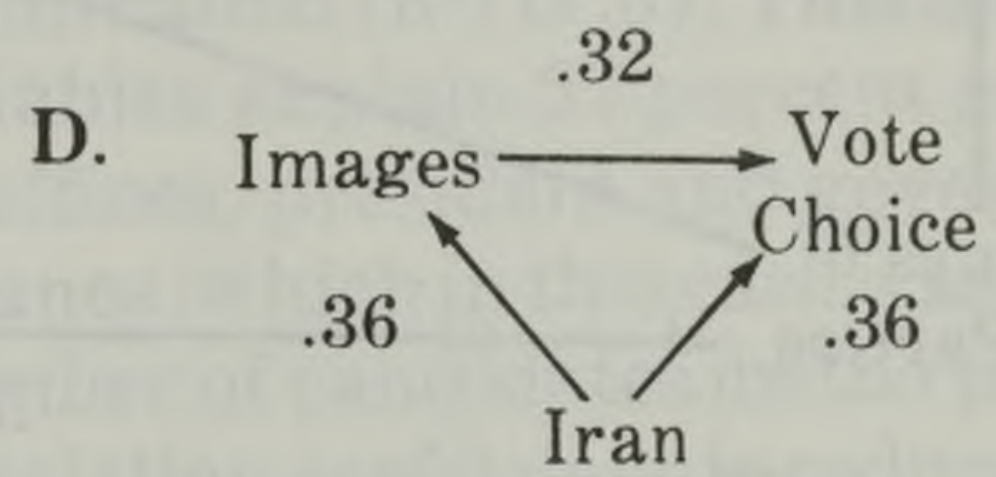

.30

F.

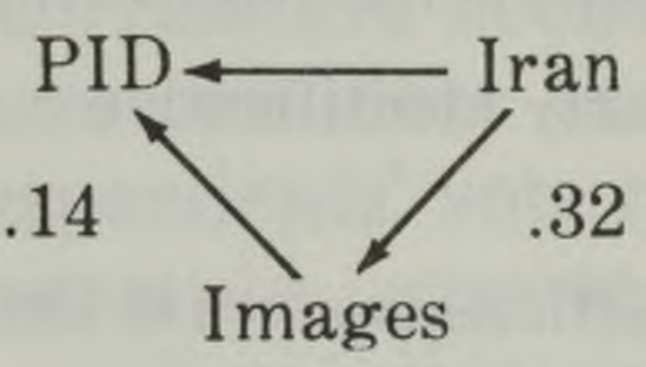

*Since the partial r's, and multiple correlations, are not based on product-moment correlation, the analysis-of-variance tests for significance have been omitted.

degree of association with vote choice. Atypically, party identification has a comparatively low correlation with vote choice, but this can be explained by the fact that salient issues and party images tend to be sensitive, leading indicators of a changing electorate, whereas party identification is a more rigid, lagging indicator. ${ }^{20}$ Party identification lags behind other indicators . because of the time needed for the reinforcement of the association after the initial vote choice has been made. ${ }^{21}$ 


\section{Figure Four}

Path Analysis of Four-Variable Model (a)

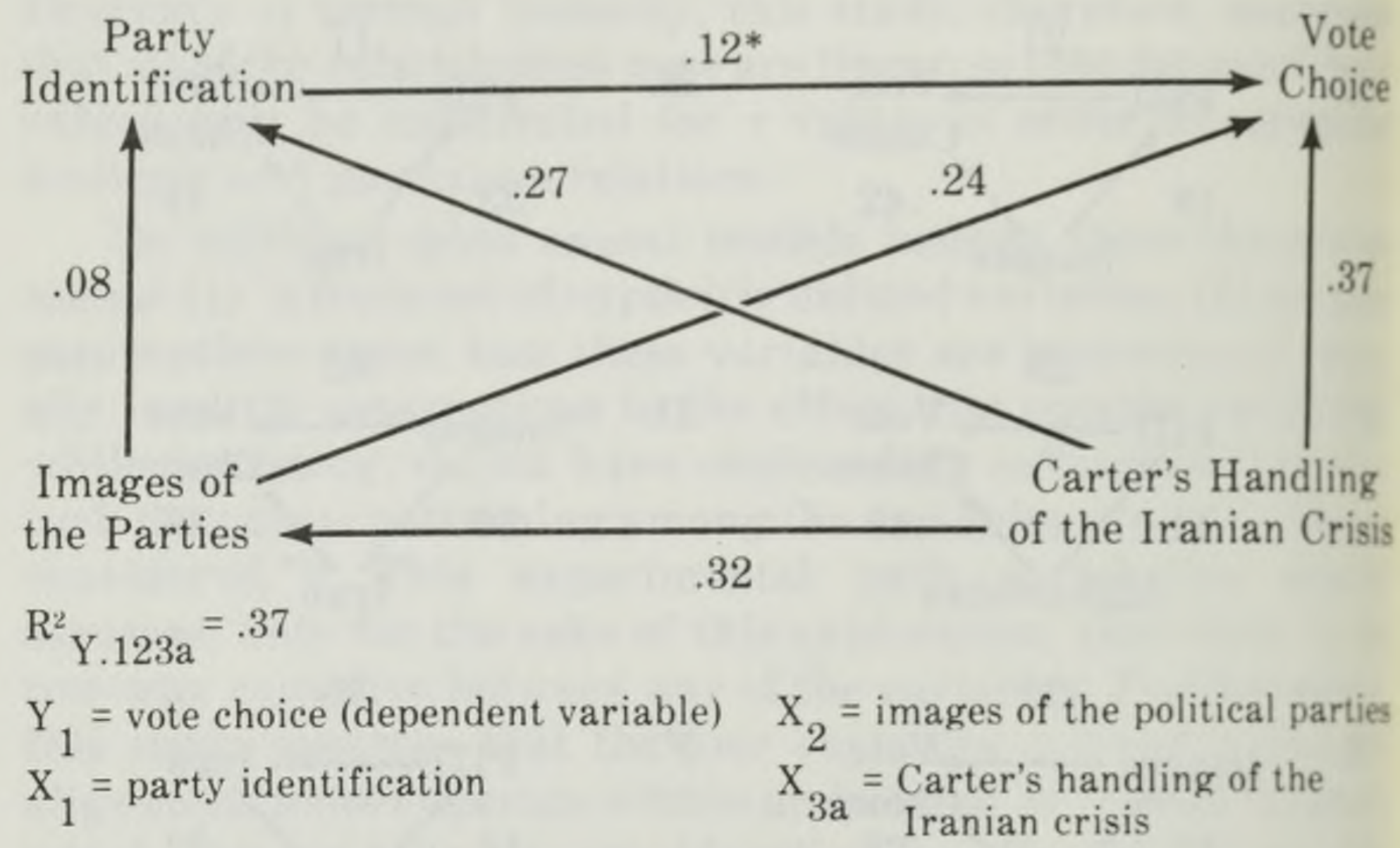

*All coefficients given in the path analysis are partial correlations coefficients.

\section{Figure Five}

Path Analysis of Four-Variable Model (b)

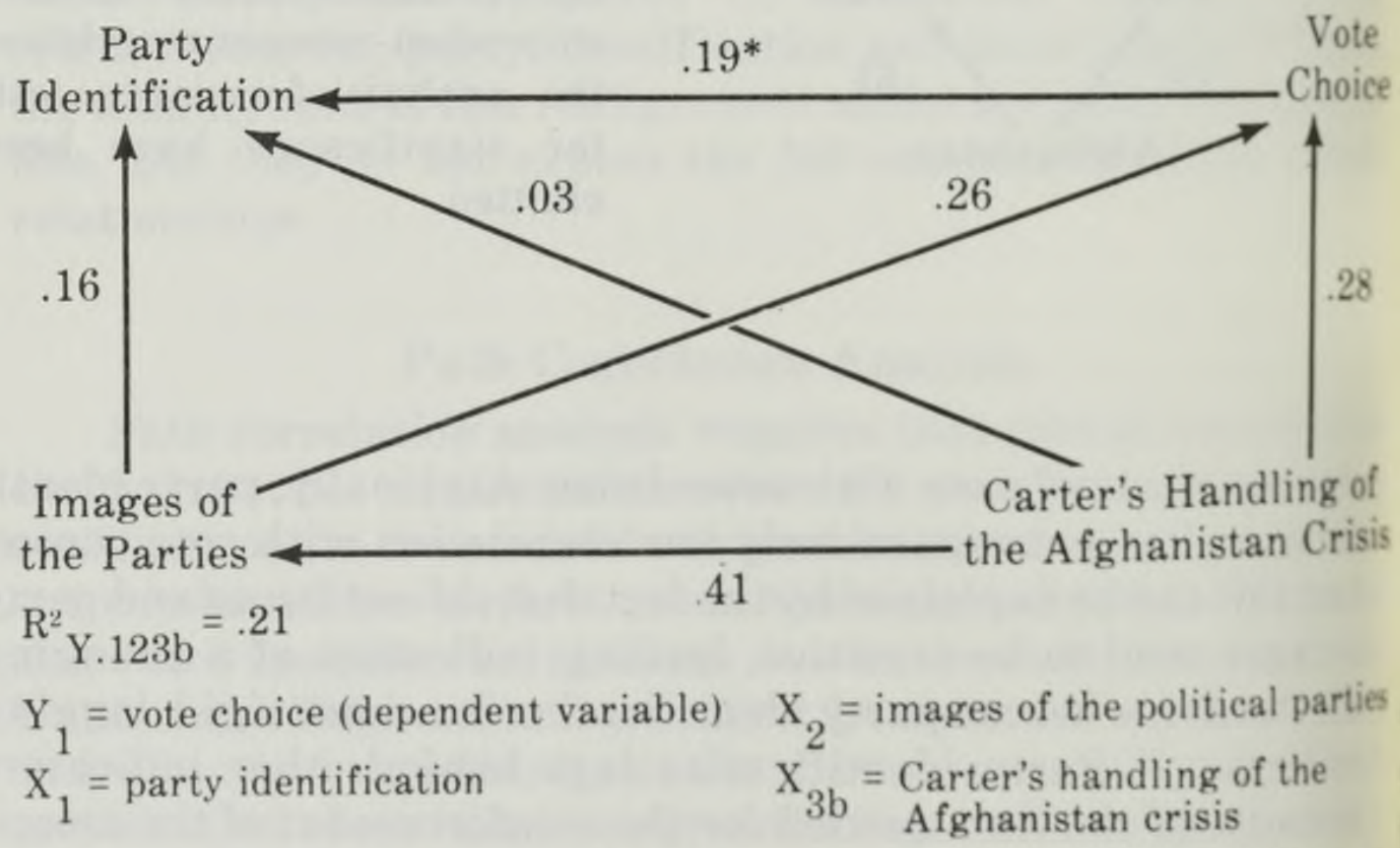

*All coefficients given in the path analysis are partial correlations coefficients. 
Since partial correlations measure only the relationships between the dependent variable and each of the independent variables separately, a multiple correlation is needed to measure the explanatory power of all three of the independent variables simultaneously. The multiple correlation coefficients for both issue questions are presented in Figures Four and Five along with sketches of the path analysis and the partial correlations. With Carter's handling of the Iranian crisis as the issue variable, the coefficient of determination $\left(R^{2}\right)$ is .37 . This means that the three independent variables explain 37 percent of the variance of vote choice for two offices, president and governor, in addition to the variance by chance, which in this case was only 7.1 percent, due to the great number of candidates on the presidential ballot. The multiple correlation coefficient is reduced to .21 when Carter's handling of the Afghanistan crisis is substituted into the model. Both of these correlation coefficients indicate fairly strong associations if one considers that this realignment model is predicting the respondents' vote choices for two offices instead of just one. For example, suppose that a respondent's candidate preference for governor is known. If the respondent's party identification, his images of the parties, and his stand on Carter's handling of the Iranian crisis are known, one may be able to predict the respondent's candidate preference for president with approximately 51 percent accuracy by using this realignment model.

\section{Conclusion}

The realignment model described in this paper has several significant strengths which have not yet been delineated. First, this empirical study is based on individual data, as opposed to ecological data, collected from registered voters in central Arkansas during the two weeks prior to the 1980 general election. Second, several of the most important variables influencing vote choice are identified, and the interaction and reinforcement among these variables is explored in a scientific manner. This realignment model is also an additive model which can be reconstructed with additional issues (economic, social, domestic, etc.) to test their influence on vote choice. The 
relationship between party identification and vote choice does not appear to be very strong, but this association probably would be strengthened if the campaign variables were added to the realignment model, because party affiliation is strongest through the candidates and their campaigns. Finally, this model increases one's power of prediction. One may be able to predict 37 percent, beyond chance, of the electorate's vote choice for both president and governor by knowing three important variables. If candidate preferences for governor are also known, one may be able to predict about 51 percent of the vote for president-possibly enough to predict the winner!

This realignment model also has several limitations which need to be pointed out. The realignment model presented here is strictly an exploratory model which does not consider many of the complexities of the vote choice model, e.g., two-way causality, outside variables, and controls for other effects. Furthermore, this model deals specifically with data collected from central Arkansas, and its predictive power cannot be extended to the state level without extreme risk. And finally, it remains to be seen if the realignment identified in this study is a permanent effect or only a temporary adjustment among the central Arkansas electorate.

\section{Notes}

Acknowledgements: The author wishes to thank Dr. Ferris Baker and all of the Hendrix College students involved in the fall 1980 Central Arkansas Survey. Special thanks go to Dr. Gene E. Bigler who conceived, developed, and oversaw all aspects of the survey, and who volunteered professional guidance for this paper. The responsibility for any errors or inadequacies rests solely on the author's shoulders.

1. Norman Nie, Sidney Verba, and John Petrocik. The Changing American Voter, rev. edl. (('ambridxe: Harvard University Press. 1979).

2. Cierald Pomper et al. The Election of 1976 (New York: D). MeKay Company. 1977). Also see "From confusion to ("larity: Issues and the American Voters. 1956-1968." American Political Science Review (.June. 1972), pr. 415-428.

3. Paul Allen Beck. "Partisan Dealignment in the Postwar South." American Political Science Review (June. 1977). Mp. 477-496.

4. Walter Dean Burnham. Critical Elections and the Mainsprings of American Politica (New York: W. W. Norton and (omplany' Inc.. 1970).

5. (iene F. Bigler. Michael A. Nigkel, and Ferris Baker, "Some Determinants of Split-Ticket Voting in Arkansas Elections." a paper prepared for presentation at the 1981 Arkansas Political Science Association Meeting.

ii. Ilicil. InI 16-18.

7. Illirl.

8. Illiil.

9. Iliill. 1). 8 . 
10. The question asked was. "(ienerally speaking, do you usually think of yourself as a Republican, a Democrat, or what?" If the respondent replies Republican or Democrat, he is asked. "Do you consider yourself to be a strong or not so) strong Republican/Democrat?" On the other hand, if the respondent says he is an Independent or that he supports some other party. then he is asked. "Do you consider yourself to be closer to the Democrats, or the Republicans?" A ladder scale is then formed in this manner:

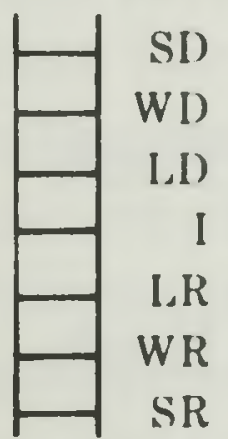

$$
\begin{aligned}
\text { SD } & =\text { strong Democrat } \\
W D & =\text { weak Democrat } \\
L D & =\text { leans Democrat } \\
I & =\text { Independent } \\
\text { LR } & =\text { leans Republican } \\
W R & =\text { weak Republican } \\
\text { SR } & =\text { strong Republican }
\end{aligned}
$$

11. Nie. Verba, and Petrocik. 1979. Also see Angus Campbell et al., The American Voter (New York: Wiley, 1960).

12. Bigler. Niggel, and Baker. 1981, p. 15. Also see (iene E. Bigler. "The World Is ('losing in on Arkansas: International Relations and Public Opinion in the Heartland." a paper prepared for presentation at the 1981 Arkansas Political Science Association Mecting.

13. The (del $k(\nabla k)$ statistic used in this study is for nominal data, and the del/( $\nabla /)$ used is for ordinal data. For further information about the del statistics. see Bigler. Niggel, Baker. 1981, p). 7-8, or Robert Bernstein and James A. Dyer. An Introduction to Political Science Methods (Englewood (liffs: Prentice-Hall. 1979).

14. Bigler. Niggel. and Baker. 1981. p. 17.

15. Ilirl., 1). 15.

16. Ihid.. 1). 16.

17. Robert Bernstein and James Dyer. An Introduction to Political Science Methods (Englewood Cliffs: Prentice-Hall, 1979). p. 193.

18. Hubert Blalock. Causal Inferences in Nonexperimental Research (Chapel Hill: University of North ('arolina Press, 1964), p). 6i2.

19. (iregory Markus and Philip Converse. "A I)ynamic Simultaneous Equation Model of Electoral (hoice." American Political Science Review (I)ecember. 1979), p). 1055-107().

20. Bigler, Niggel, and Baker. 1981, p. 12.

21. Markus and Converse. 1979, Mp). 1(155-1070. 